\title{
Vascular mild cognitive impairment and its relationship to hemoglobin A1c levels and apolipoprotein E genotypes in the Dominican Republic
}

\author{
Martin Medrano ${ }^{1 \oplus}$, Gelanys Castro-Tejada ${ }^{1,2}{ }^{\oplus}$, Rafael Lantigua ${ }^{3,4}{ }^{\oplus}$, Gretel Silvestre $^{5,6}{ }^{\circ}$, \\ Sergio Diaz ${ }^{1,7,8}$, Patricia Mota ${ }^{6}$, Franck Diaz-Garelli9๑
}

\begin{abstract}
Dementia and vascular mild cognitive impairment (VaMCI) currently impose a tremendous human and economic burden on patients from aging populations and their families worldwide. Understanding the interplay of cardiometabolic risk factors and apolipoprotein $\mathrm{E}$ (APOE) may direct us to a more personalized medicine and preventative care in $\mathrm{MCl}$ and dementia. Objective: To evaluate the relationship of cardiometabolic risk factors with $\mathrm{MCl}$ and assess the APOE genotype's role in an elderly cohort in the Dominican Republic. Methods: We studied a cohort of 180 participants 65 years of age and older using a combined assessment of cardiometabolic risk factors, neuropsychological battery tests, and APOE genotyping. We used the number of failed tests as a proxy to predict MCl. Results: We found that patients with the $\varepsilon 3-\varepsilon 4$ APOE genotype had 2.91 higher number of failed cognitive tests $(p=0.027)$ compared to patients with the $\varepsilon 3-\varepsilon 3$ genotyped. The rate of test failures increased $10 \%(p=0.025)$ per unit increase in HbA1c percentage. Conclusions: Increased Hemoglobin A1c levels and $\varepsilon 3-\varepsilon 4$ APOE genotypes seem to have an association with the development of $\mathrm{VaMCl}$.
\end{abstract}

Keywords: vascular dementia, risk factors, apolipoproteins E, metabolic syndrome, diabetes mellitus.

\section{COMPROMETIMENTO COGNITIVO LEVE VASCULAR E SUA RELAÇÃO COM OS NÍVEIS DE HEMOGLOBINA A1C E GENÓtIPOS APOLIPOPROTEINA E NA REPÚBLICA DOMINICANA}

RESUMO. A demência e o comprometimento cognitivo leve vascular ( $\mathrm{VaMCl}$ ) atualmente impõem uma enorme carga humana e econômica aos pacientes de populações envelhecidas e suas famílias em todo o mundo. Compreender a interação dos fatores de risco cardiometabólicos e apolipoproteína E (APOE) pode nos direcionar para uma medicina mais personalizada e de cuidados preventivos em $\mathrm{MCl}$ e demência. Objetivo: Avaliar a relação dos fatores de risco cardiometabólicos com o MCl e o papel do genótipo APOE em uma coorte de idosos na República Dominicana. Métodos: Estudamos uma coorte de 180 participantes com 65 anos de idade ou mais, utilizando uma avaliação combinada de fatores de risco cardiometabólicos, uma bateria de testes neuropsicológicos e genotipagem APOE. Adotou-se o número de testes com mau desempenho para o diagnóstico de $\mathrm{MCl}$. Resultados: Verificou-se que os pacientes com o genótipo $\varepsilon 3-\varepsilon 4$ do APOE apresentaram 2,91 vezes mais testes cognitivos com mau desempenho $(p=0,027)$ em comparação com os pacientes com o genótipo $\varepsilon 3-\varepsilon 3$. A taxa de falhas de teste aumentou $10 \%(p=0,025)$ por aumento de unidade na porcentagem de HbA1C. Conclusões: Níveis mais altos de HbA1C e os genótipos $\varepsilon 3-\varepsilon 4$ do APOE parecem estar associados ao desenvolvimento de $\mathrm{VaMCl}$.

Palavras-chave: demência vascular, fatores de risco, alipoproteínas E, síndrome metabólica, diabetes mellitus.

\footnotetext{
This research was conducted by School of Medicine, Pontificia Universidad Católica Madre y Maestra, and carried out at the Geriatrics Services at Hospital Regional Universitario José Maria Cabral y Baez, as well as, in Clínica Corominas, Santiago, Dominican Republic.

'School of Medicine, Pontificia Universidad Católica Madre y Maestra - Santiago, Dominican Republic. ${ }^{2}$ Biomedical and Clinical Research Center, Hospital Universitario José Maria Cabral y Baez - Santiago, Dominican Republic. ${ }^{3} T$ The Taub Institute for Research on Alzheimer's Disease and the Aging Brain - New York, NY, USA. ${ }^{4}$ Department of Medicine, Columbia University, The New York Presbyterian Hospital - New York, NY, USA. ${ }^{5}$ Neuroscience and Behavior Research Program, Pontificia Universidad Católica Madre y Maestra - Santiago, Dominican Republic. ${ }^{\circ}$ School of Psychology, Pontificia Universidad Católica Madre y Maestra - Santiago, Dominican Republic. ${ }^{7}$ Internal Medicine Service at Hospital Universitario Jose Maria Cabral y Baez - Santiago, Dominican Republic. ${ }^{8}$ Department of Preventive Medicine, Hospital Metropolitano de Santiago - Santiago, Dominican Republic. ${ }^{9}$ University of North Carolina at Charlotte - Charlotte, USA.
}

Gelanys Castro-Tejada. 45-10 Kissena Blvd Apt. 5B Flushing NY 11355. E-mail: gcastro.md@gmail.com

Funding: This work was supported by the Dominican Republic National Funding of Technologic and scientific Development and Innovation (FONDOCYT) grant: 2013-2A3-117.

Disclosure: The authors report no conflicts of interest.

Received on May 28, 2020. Accepted in final form on December 29, 2020. 


\section{INTRODUCTION}

$\mathrm{D}$ ementia and vascular mild cognitive impairment (VaMCI) currently impose a tremendous human and economic burden on patients from aging populations and their families worldwide. ${ }^{1} \mathrm{VaMCI}$ encompasses the cerebrovascular continuum from $\mathrm{MCI}$ to dementia, ${ }^{2}$ beginning with cardiometabolic risk factors leading to cerebral vascular disease (CVD) of the large and small arteries. This disease will lead to different types of cognitive impairments depending on the location of the damage produced..$^{3-5}$ Associated risk factors comprise the entire cluster of classical vascular risks: Hypertension (HTN), hyperlipidemia, Diabetes Mellitus Type 2 (DM2), metabolic syndrome (MetS), smoking, and age but also the emerging risk factors: ${ }^{6}$ high sensitivity $\mathrm{C}$-reactive protein and homocysteine, behaving as pro-inflammatory markers and prothrombotic status, respectively. When vascular diseases have been associated with $\mathrm{MCI}$, the incidence in patients with at least one vascular disease doubles the frequency of $\mathrm{MCI}$ in the healthy population. ${ }^{7}$ HTN also seems to have a strong influence when developed during mid-adulthood as compared to its appearance in an older age. ${ }^{8}$

DM2 has also been associated with executive function impairment, including reasoning, mental flexibility, problem solving, and decision making; especially with high glucose levels, worst performance on executive cognitive tasks was seen when DM2 would onset in midlife. ${ }^{9}$ Evidence for the relationship between diabetes and vascular dementia has been consistent, ${ }^{10}$ both the American Diabetes Association (ADA) and the American Heart Association (AHA) have stated the need to develop reliable estimates of the combined cardiometabolic risks for patient care. ${ }^{11}$ Metabolic syndrome, as well, encompasses multiple coexisting factors associated with cognitive function decline in elderly populations. ${ }^{12,13}$ However, most cardiovascular risk factors are modifiable; genetics are also likely to play a role. ${ }^{14}$ Understanding this interplay may unlock the promise of personalized medicine and preventive care in $\mathrm{MCI}$ and dementia. ${ }^{15}$ The presence of at least one allele of apolipoprotein $\mathrm{E}$ (APOE) $\varepsilon 4$ is a risk factor for cardiovascular diseases and increases the risk of dementia in subjects who have suffered a stroke, ${ }^{16,17}$ being particularly pronounced factors in the Latino population..$^{18} \mathrm{APOE}$ is involved in lipid metabolism and can modulate the relationship between vascular factors, diabetes, and cognitive functions. ${ }^{19,20}$

The geriatric neuropsychological battery (NPB) is a great tool to identify patients with $\mathrm{MCI}$ at risk of progressing to dementia. ${ }^{21}$ In conjunction with NPB, early identification of vascular risk factors and treatment of associated diseases may decrease vascular cognitive impairment incidence. ${ }^{17}$ However, the literature is still unclear about the interplay between APOE genotypes, cardiometabolic risk factors, and cognitive impairment. This research group investigated cardiometabolic risk factors to address this gap, aiming to convey findings that may lead to the development of clinical protocols for early prevention, diagnosis, and treatment of cognitive changes in aging patients. The objective of this study was to evaluate the relationship of cardiometabolic risk factors with $\mathrm{MCI}$ and to assess the role of the APOE genotype in an elderly cohort in the ethnically heterogeneous Dominican Republic.

\section{METHODS}

\section{Study description}

The Cardiometabolic, Cerebral and Genetic Factors and Their Influence on Neurocognitive Functions and Depression in the Elderly (CEGENED) study, was conducted in Santiago, Dominican Republic. The cohort comprised 180 subjects aged 65 years old or older, both male and female. The study period lasted four years. For this paper, the first assessment, performed between July 2014 and May 2015, was analyzed. The purpose of the study and the participants' role were written, and verbally explained, following the evaluation of the participants' comprehension of its benefits and consequences. They proceeded to sign the consent form, per protection of human subject standards. Participants were invited from primary care consultations to community gatherings, where objectives of the study were explained. An initial interview assessed demographic variables, including age and gender, and self-reported level of education. During the visit, an in-depth medical history was also conducted, in addition to a biophysical medical evaluation, Columbia University validated neuropsychological battery tests, ${ }^{22}$ and a Depressive Symptoms (Center for Epidemiologic Studies Depression Scale - CES-D) test. ${ }^{23}$ Smoking for more than a month and any history of alcohol intake were self-reported.

Inclusion criteria were:

- Dominican citizens aged 65 years old or older;

- No history of CVD or depression;

- Being able to perform basic and instrumental activities of daily living autonomously (Lawton and Brody Scale, ${ }^{24}$ and Barthel Index). ${ }^{25}$

- Being able to use public transportation independently and apparent normal cognition (short Blessed test ${ }^{26}$ score). 
Exclusion criteria were:

- History or evidence of stroke.

- Myocardial infarction.

- Neurological or psychiatric conditions such as psychotic disorders or bipolarity.

- Alcoholism (intake greater than 30 gr a day for men and 20 gr a day for women).

- History of brain surgery.

This study was approved by the Committee of Bioethics of the Pontificia Universidad Católica Madre y Maestra (COBE-FACS) and the National Committee on Bioethics (CONABIOS): 002-2-2013-2014.

\section{Cardiometabolic evaluation}

Cardiometabolic factors were assessed using the diagnostic criteria described in the AHA guidelines. ${ }^{27}$ DM was considered in anyone with prior diagnosis or who is currently being treated with glucose-lowering medication. Diagnosis would be made if there was no history of diabetes, but a fasting glucose level greater than $126 \mathrm{mg} / \mathrm{dL}$ or HbA1c level greater than $6.5 \%$. Hypertension is defined as systolic blood pressure $\geq 130 \mathrm{mmHg}$ and diastolic blood pressure $\geq 80 \mathrm{mmHg}$. Diagnosis was made according to the 24-hour Ambulatory Blood Pressure Monitoring report for anyone with prior diagnosis or currently treated with antihypertensive medications, or HTN diagnosis status unknown. The lipid profile was determined using standard enzymatic techniques. High-density lipoprotein cholesterol (HDL-C) was determined using a cholesterol laboratory standard method for CVD biomarkers. High sensitivity C-reactive protein was measured using an ultrasensitive enzyme-linked immunosorbent assay. Criteria of the Third Report of the National Cholesterol Education Program Expert Panel of Detection, Evaluation and Treatment of High Blood Cholesterol in Adults (Adult Treatment Panel III), were used to determine the metabolic syndrome if three or more of the following criteria coexisted: Abdominal obesity determined by a waist circumference greater than $102 \mathrm{~cm}$ in men and $88 \mathrm{~cm}$ in woman, triglycerides greater than or equal to $150 \mathrm{mg} / \mathrm{dL}, \mathrm{HDL}-\mathrm{C}$ lower than $40 \mathrm{mg} / \mathrm{dL}$ in men and $50 \mathrm{mg} / \mathrm{dL}$ in women, HTN diagnosed previously or by the Holter during the study, and diabetes previously diagnosed or an $\mathrm{HbA1}$ c greater than $6.5 \%$. Homocysteine levels were determined by the Abbott homocysteine (HCY) assay considering normal values of up to $15 \mu \mathrm{mol} / \mathrm{L}$. APOE genotyping was performed at Columbia University in the Taub Institute for Research on Alzheimer's Disease and the Aging Brain using a polymerase chain reaction-based method. APOE genotype was determined by Polymerase Chain Reaction-Restriction Fragment Length Polymorphism (PCR-RFLP) using the enzyme HhaI. ${ }^{28-30}$

\section{Neuropsychological assessment}

All participants were cognitively normal according to the initial Short Blessed Test assessment. The neuropsychological battery ${ }^{22}$ was then applied, including the following tests and their cut-off values:

- Memory (Selective Reminding Test total recall $<25$, Selective Reminding Test long-term recall $<15$, Selective Reminding Test delayed recall $<4$, Delayed recognition $<8$, Benton Visual retention Test multiple choice recognition $<7$ ).

- Orientation $<8$.

- Construction (Benton Visual retention test multiple-choice matching $<7$ ).

- Abstract reasoning (Mattis identities and oddities $<12$ ).

- Language (Boston Diagnostic Aphasia Evaluation repetition of high probability phrases $<7$, Boston Diagnostic Aphasia Evaluation complex ideation material $<5$, Boston Naming Test $<11$ ).

- Controlled Oral word association $<16$ percentile.

Subject differences were explored along two dimensions: patients who scored below the tests' cutoff values classified as MCI patients versus not along with the raw number of failed cognitive tests per patient. All participants underwent brain magnetic resonance imaging (MRI) to determine vascular brain damage status.

\section{Imaging techniques}

Noninvasive cardiologic and brain imaging studies included: Electrocardiogram and echocardiogram, brain magnetic resonance with Brain MRI (Toshiba 1.5 tesla): Coronal section cuts of $0.3 \mathrm{~mm}$. Axial and sagittal section cuts of $4 \mathrm{~mm}$ in T1, T2, and FLAIR. Also, white matter hyperintensities and brain atrophy were assessed by the FAZEKAS visual scales. Anterior and posterior extracranial circulation was evaluated by carotid Doppler using Mindray M7 Duplex Scan equipment of high-resolution 3D/4D color images, B-mode, with 7L4sMHZ transducer. Thickening of the medial intima greater than or equal to $1.0 \mathrm{~mm}$ was considered stenotic and associated with atherosclerosis.

\section{Diagnosis of vascular mild cognitive impairment}

The diagnosis of VaMCI was based on the new criteria proposed by the International Society for Vascular Behavioral and Cognitive Disorders (VASCOG) ${ }^{31}$ comprising two main categories: 
- The cognitive deficits are not sufficient to interfere with independence (i.e., instrumental activities of daily living are preserved), but greater efforts, compensatory strategies, or accommodation may be required to maintain independence.

- Determining that vascular disease is the dominant or exclusive cause of cognitive deficits.

Cognitive performance impairment in neuropsychological assessment was considered when between 1 and 2 standard deviations below the norm, or between the $3 \mathrm{rd}$ and 16th percentile in individuals of similar age, gender, education, and sociocultural backgrounds. One of the exclusion criteria was the history of known stroke. Subjects with large vessel disease or atherothrombotic diseased patients were also excluded. For the deemed VaMCI, we have considered silent infarcts, small vessel disease: multiple lacunar infarcts in the white substance or the gray matter of the basal nuclei, extensive and confluent vascular leukopathy (Fazekas II-III scale), microinfarcts, and cortical microhemorrhages.

\section{Statistical analysis}

For this analysis, the number of test failures were assessed as a proxy to predict the intensity of VaMCI in each patient, as done in previous studies. ${ }^{32,33} \mathrm{~A}$ test was considered failed when its cognitive test score was below the cut-off value. We explored initial associations with univariate models predicting VaMCI in patients with a binomial regression and the number of failed tests with count regressions. Multivariate count regressions were built to predict the number of neuropsychological tests failed using R's generalized linear model (GLM). ${ }^{34}$ We tested our datasets for zero inflation using the Van den Broek's zero-inflation test ${ }^{35}$ and for overdispersion by comparing means and standard deviations in our primary outcome variable (i.e., number of failed tests). We selected classic Poisson regressions to fit our non-zero-inflated, non-over-dispersed data. For all the models, the number of failed tests was this study's primary outcome variable. Models were built using a forward selection process. Specifically, there was a pre selection of variables based on predictive power according to Harell's variable selection approach, ${ }^{36}$ setting the $\mathrm{p}$-value variable inclusion threshold at 0.1 . Then, each pre-selected variable's relationship to VaMCI and APOE genotypes were explored. The Akaike's information criterion was used to select the final model by maximizing each model's goodness of fit. ${ }^{37}$ All models were tested for variable interactions and collinearity effects with more than one variable. Adjustments for multiple comparisons were made using R's p. adjust function, selecting
Holm's correction method. ${ }^{38}$ Statistical significance was set at $\mathrm{p}=0.05$ for all models.

\section{RESULTS}

180 participants were recruited, two died before completing data collection, and two were lost to follow up. This study's final cohort contained 176 participants, with $70.5 \%$ of the total sample affected by Non-VaMCI (Table 1). Age ranges from 65 to 77 years, with $30.11 \%$ males and $69.3 \%$ females. $58.86 \%$ of patients had a history of HTN, $25.5 \%$ had a history of diabetes, and $68.18 \%$ completed primary education. Mean systolic blood pressure

Table 1. Demographics, cardiometabolic risk factors, genetic, and neuropsychological assessments.

\begin{tabular}{|c|c|c|c|}
\hline Characteristics & $\begin{array}{c}\text { Non-VaMCI } \\
(n=127)\end{array}$ & VaMCI $(n=49)$ & p-value \\
\hline Age (years) & $71 \pm 6.03$ & $73 \pm 6.28$ & 0.863 \\
\hline Female (\%) & $88(69.3)$ & $35(71.4)$ & 0.0649 \\
\hline Education (years) & $5.49 \pm 3.31$ & $4.95 \pm 2.67$ & 0.992 \\
\hline Diabetes mellitus & $31(24.4 \%)$ & $12(24.5 \%)$ & 0.901 \\
\hline Hypertension & $70(55.1 \%)$ & $33(67.3 \%)$ & 0.0996 \\
\hline $\begin{array}{l}\text { Systolic blood } \\
\text { pressure }(\mathrm{mmHg})\end{array}$ & $153.39 \pm 24.88$ & $154.47 \pm 26.62$ & 0.189 \\
\hline $\begin{array}{l}\text { Diastolic blood } \\
\text { pressure }(\mathrm{mmHg})\end{array}$ & $78.68 \pm 10.67$ & $79.80 \pm 11.81$ & 0.568 \\
\hline MAP $(\mathrm{mmHg})$ & $100.53 \pm 16.60$ & $99.06 \pm 22.29$ & 0.480 \\
\hline BMI $\left(\mathrm{kg} / \mathrm{m}^{2}\right)$ & $27.6 \pm 6.99$ & $26.29 \pm 3.96$ & 0.413 \\
\hline Waist circumference $(\mathrm{cm})$ & $95.1 \pm 12.3$ & $97.06 \pm 9.96$ & 0.457 \\
\hline Total cholesterol (mg/dL) & $198.42 \pm 41.71$ & $196.28 \pm 40.96$ & 0.968 \\
\hline Triglyceride (mg/dL) & $138 \pm 80.84$ & $138.69 \pm 63.22$ & 0.980 \\
\hline LDL-C (mg/dL) & $122.6 \pm 36.7$ & $122.5 \pm 36.4$ & 0.715 \\
\hline $\mathrm{HDL}-\mathrm{C}(\mathrm{mg} / \mathrm{dL})$ & $46.66 \pm 10.85$ & $45.63 \pm 10.75$ & 0.646 \\
\hline $\mathrm{HbA1c}(\%)$ & $6.56 \pm 1.18$ & $6.69 \pm 1.18$ & 0.619 \\
\hline C-reactive protein & $5.50 \pm 8.06$ & $4.39 \pm 6.12$ & 0.217 \\
\hline Homocysteine & $17.9 \pm 6.77$ & $19.7 \pm 9.46$ & 0.856 \\
\hline Smoking & $55(47.02 \%)$ & $20(45.26 \%)$ & 0.562 \\
\hline MetS & $54(49.09 \%)$ & $21(48.84 \%)$ & 0.348 \\
\hline CES-D & $92(83.64 \%)$ & $14(12.73 \%)$ & 0.490 \\
\hline
\end{tabular}


Table 1. Continuation.

\begin{tabular}{|c|c|c|c|}
\hline Characteristics & $\begin{array}{c}\text { Non-VaMCI } \\
(n=127)\end{array}$ & VaMCI $(n=49)$ & p-value \\
\hline \multicolumn{4}{|l|}{ Neuropsychological Battery } \\
\hline \multicolumn{4}{|l|}{ Memory } \\
\hline SRT total recall & $37.69 \pm 9.69$ & $36.24 \pm 9.15$ & 0.373 \\
\hline $\begin{array}{l}\text { SRT long- } \\
\text { term recall }\end{array}$ & $24.96 \pm 12.55$ & $23.26 \pm 10.93$ & 0.451 \\
\hline SRT delayed recall & $5.48 \pm 2.35$ & $5.59 \pm 2.28$ & 0.709 \\
\hline Delayed recognition & $11.19 \pm 1.30$ & $11.16 \pm 1.32$ & 0.991 \\
\hline $\begin{array}{l}\text { BVRT } \\
\text { multiple-choice } \\
\text { recognition }\end{array}$ & $5.60 \pm 2.30$ & $5.18 \pm 2.26$ & 0.338 \\
\hline Orientation & $8.16 \pm 1.40$ & $8.02 \pm 1.24$ & 0.571 \\
\hline \multicolumn{4}{|l|}{ Construction } \\
\hline $\begin{array}{l}\text { BVRT multiple-choice } \\
\text { matching }\end{array}$ & $7.31 \pm 2.34$ & $7.26 \pm 2.06$ & 0.950 \\
\hline \multicolumn{4}{|l|}{ Abstract reasoning } \\
\hline $\begin{array}{l}\text { Mattis identities } \\
\text { and oddities }\end{array}$ & $14.90 \pm 1.26$ & $14.26 \pm 1.61$ & 1 \\
\hline \multicolumn{4}{|l|}{ Language } \\
\hline $\begin{array}{l}\text { BDAE repetition } \\
\text { of high probability } \\
\text { phrases }\end{array}$ & $7.80 \pm 0.50$ & $7.79 \pm 0.45$ & 0.756 \\
\hline $\begin{array}{l}\text { BDAE complex } \\
\text { ideation material }\end{array}$ & $4.44 \pm 1.18$ & $4 \pm 1.59$ & 0.071 \\
\hline Boston Naming Test & $13.32 \pm 1.70$ & $12.65 \pm 2.86$ & 0.105 \\
\hline CFL & $24.65 \pm 20.65$ & $20.44 \pm 18.18$ & 0.202 \\
\hline \multicolumn{4}{|l|}{ APOE genotype } \\
\hline$\varepsilon 2-\varepsilon 2$ & $1(0.79 \%)$ & & 0.996 \\
\hline$\varepsilon 2-\varepsilon 3$ & $10(7.97 \%)$ & $7(14.29 \%)$ & 0.991 \\
\hline$\varepsilon 2-\varepsilon 4$ & & $1(2.04 \%)$ & 0.988 \\
\hline$\varepsilon 3-\varepsilon 3$ & $82(65.08 \%)$ & $35(71.43 \%)$ & 0.992 \\
\hline$\varepsilon 3-\varepsilon 4$ & $30(23.81 \%)$ & $6(12.24 \%)$ & 0.992 \\
\hline$\varepsilon 4-\varepsilon 4$ & $3(2.38 \%)$ & & 0.992 \\
\hline Indeterminate & $1(0.85 \%)$ & & 1 \\
\hline
\end{tabular}

APOE: apolipoprotein E; VaMCl: vascular mild cognitive impairment; MAP: mean arterial pressure; BMI: body mass index; HDL-C: high-density lipoprotein cholesterol; LDL-C: low-density lipoprotein cholesterol; HbA1c: glycated hemoglobin; MetS: metabolic syndrome; CES-D: Center for Epidemiologic Studies Depression Scale; SRT: Selective Reminding Test; BVRT: Benton Visual Retention Test; BDAE: Boston Diagnostic Aphasia Evaluation; CFL: Controlled Oral Word Association. was at stage I hypertension (153.4 $\mathrm{mmHg}$ ), but the mean diastolic blood pressure was normal $(78.7 \mathrm{mmHg})$. Mean cholesterol was ( $198.42 \mathrm{mg} / \mathrm{dL})$, mean triglycerides was $(138 \mathrm{mg} / \mathrm{dL})$, and mean low-density lipoprotein cholesterol (LDL-C) was $(122.6 \mathrm{mg} / \mathrm{dL})$, while the mean glycated hemoglobin was $6.6 \%$, characterizing diabetes. Exploring group differences and statistically significant relationships between our variables and VaMCI groups, no statistically significant relationships were observed, likely due to the limited cohort size.

Demographic data of all aged patients comparing VaMCI and non-vascular cognitive impairment. MAP: mean arterial pressure; BMI: body mass index; LDL-C: low-density lipoprotein cholesterol; HDL-C: high-density lipoprotein cholesterol; HbA1c: glycated hemoglobin; MetS: metabolic syndrome; CES-D: Center for Epidemiologic Studies Depression Scale; SRT: Selective Reminding Test; BVRT: Benton Visual Retention Test; WAIS-R: Wechsler Adult Intelligence Scale-Revised; BDAE: Boston Diagnostic Aphasia Evaluation; CFL: Controlled Oral Word Association; APOE: apolipoprotein E genotypes. Even though there was genotype variability among participants, we chose to focus on APOE $\varepsilon 3-\varepsilon 3$ and $\varepsilon 3-\varepsilon 4$ due to data availability. Statistical differences were evaluated with univariate logistic regression models predicting patient's belonging to the VaMCI group or not. Values are mean \pm standard deviations or $\mathrm{n}(\%)$.

Our population presented a high rate of cognitive test failures (i.e., a cognitive test score below its cutoff value) for patients with both APOE genotypes of interest (Table 2). We report the overall number of failed tests for each cognitive category tested; therefore, the number of failed tests is higher than the number

Table 2. Number of patients with failed cognitive tests and number of test failure. Statistical differences were evaluated with univariate logistic regression models predicting patient's belonging to each apolipoprotein E group.

\begin{tabular}{lccc}
\hline Area impaired & $\begin{array}{c}\text { APOE } \varepsilon 3-\varepsilon 3 \\
\mathbf{n}=\mathbf{1 1 7}\end{array}$ & $\begin{array}{c}\text { APOE } \varepsilon 3-\varepsilon 4 \\
\mathbf{n}=36\end{array}$ & p-value \\
\hline Memory & $6(5.08 \%)$ & $4(11.11 \%)$ & 0.231 \\
\hline Orientation & $29(24.58 \%)$ & $16(44.44 \%)$ & 0.0608 \\
\hline Construction & $117(100 \%)$ & $36(100 \%)$ & 1 \\
\hline Abstract reasoning & $117(100 \%)$ & $36(100 \%)$ & 1 \\
\hline Language & $80(67.80 \%)$ & $28(77.78 \%)$ & 0.280 \\
\hline $\begin{array}{l}\text { Overall number of failed } \\
\text { tests (\% of total tests) }\end{array}$ & $578(32.9 \%)$ & $207(38.7 \%)$ & 0.0609 \\
\hline
\end{tabular}

APOE: apolipoprotein E. 
of patients in the cohort. Construction and Abstract reasoning tests had close to $100 \%$ failure rates for both genotypes, whereas language tests showed no differences ( 67.80 vs. $77.78 \%$ for $\varepsilon 3-\varepsilon 3$ and $\varepsilon 3-\varepsilon 4$ genotypes, respectively). Nevertheless, we found significant differences for orientation tests ( $24.58 \mathrm{vs.} 44.44 \%$ for $\varepsilon 3-\varepsilon 3$ and $\varepsilon 3-\varepsilon 4$, respectively). Memory tests, however, presented low failure rates: $6 v s .4$ test failures overall, corresponding to 5.08 vs. $11.11 \%$ failure rates of $\varepsilon 3-\varepsilon 3$ and $\varepsilon 3-\varepsilon 4$, respectively. The mean failure rates were relatively similar, with $4.92+-2.25$ and $5.75+-2.26$ for APOE genotypes $\varepsilon 3-\varepsilon 3$ and $\varepsilon 3-\varepsilon 4$, respectively. Near-significant group differences were found between $\varepsilon 3-\varepsilon 3$ and $\varepsilon 3-\varepsilon 4$ APOE groups for orientation tests and the overall number of test failures.

Our preliminary cardiometabolic risk factor variable screening based on their relationships with the number of failed cognitive tests revealed statistically significant relationships for mean arterial pressure, waist circumference, weight, and $\mathrm{HbA1c}$ (Table 3).

This study's final model predicting overall test failures disclosed statistically significant relationships between the number of failed tests, the APOE genotype, and the patients' HbA1c levels at the day the tests were administered (Table 4). HbA1c, waist circumference, weight,

Table 3. Statistical association between individual cardiometabolic risk factors and the number of failed cognitive tests using a count model using the full cohort sample.

\begin{tabular}{|c|c|c|c|c|c|c|}
\hline Term & $\begin{array}{c}\text { Rates ratio } \\
(\exp (B))\end{array}$ & $\begin{array}{c}\text { Estimate } \\
\text { (B) }\end{array}$ & \multicolumn{2}{|c|}{ 95\% confidence interval } & Standard error & p-value \\
\hline Gender & 1.053 & 0.0524 & $(-0.099$ & $0.201)$ & 0.076 & 0.493 \\
\hline Age & 1.005 & 0.0055 & $(-0.005$ & $0.016)$ & 0.005 & 0.335 \\
\hline Hypertension & 1.114 & 0.1080 & $(-0.033$ & $0.251)$ & 0.072 & 0.137 \\
\hline Diabetes & 1.089 & 0.0859 & $(-0.0827$ & $0.249)$ & 0.084 & 0.310 \\
\hline $\mathrm{HbA1} c^{*}$ & 1.054 & 0.0533 & $(-0.0054$ & $0.109)$ & 0.029 & 0.069 \\
\hline Waist circumference ${ }^{\star}$ & 0.747 & -0.2905 & $(-0.545$ & $-0.035)$ & 0.130 & 0.025 \\
\hline BMI & 0.994 & -0.0055 & $(-0.020$ & $0.009)$ & 0.007 & 0.474 \\
\hline Weight* & 0.993 & -0.0060 & $(-0.011$ & $-0.0005)$ & 0.002 & 0.031 \\
\hline Triglyceride & 0.999 & $-7.90 \mathrm{E}-05$ & $(-0.001$ & $0.0008)$ & 0.000 & 0.870 \\
\hline HDL-C & 0.995 & -0.0048 & $(-0.011$ & $0.001)$ & 0.003 & 0.147 \\
\hline LDL-C & 1.000 & 0.0007 & $(-0.001$ & $0.0026)$ & 0.000 & 0.428 \\
\hline $\mathrm{MAP}^{*}$ & 1.132 & 0.1242 & $(-0.017$ & $0.266)$ & 0.072 & 0.086 \\
\hline
\end{tabular}

HDA1c: glycated hemoglobin; BMI: body mass index; HDL-C: high-density lipoprotein cholesterol; LDL-C: low-density lipoprotein cholesterol; MAP: mean arterial pressure. Variables presenting a relationship with the number of failed cognitive tests are marked with an asterisk. Statistical differences were evaluated with univariate count regression models predicting the number of failed tests for each patient.

Table 4. Final count regression model predicting the number of overall failed tests for the full patient cohort.

\begin{tabular}{|c|c|c|c|c|c|c|c|}
\hline \multirow{2}{*}{$\begin{array}{l}\text { Regression term } \\
\text { Intercept }\end{array}$} & \multirow{2}{*}{$\begin{array}{c}\begin{array}{c}\text { Rates ratio } \\
(\exp (B))\end{array} \\
2.59\end{array}$} & \multirow{2}{*}{$\begin{array}{c}\text { Estimate (B) } \\
0.95\end{array}$} & \multicolumn{2}{|c|}{$\begin{array}{c}\text { Confidence } \\
\text { interval (95\%) }\end{array}$} & \multirow{2}{*}{$\begin{array}{c}\text { Standard error } \\
0.249\end{array}$} & \multirow{2}{*}{$\frac{p \text {-value }}{0.0001}$} & \multirow{2}{*}{$\begin{array}{c}\begin{array}{c}\text { Adjusted } \\
\text { p-value }\end{array} \\
0.0005\end{array}$} \\
\hline & & & $(0.470$ & 1.45) & & & \\
\hline APOE $\varepsilon 3-\varepsilon 3$ (Reference) & 1 & 1 & - & & - & - & - \\
\hline APOE $\varepsilon 3-\varepsilon 4$ & 2.91 & 1.07 & $(0.228$ & 1.93) & 0.434 & 0.013 & 0.027 \\
\hline $\mathrm{HbA1c}$ & 1.10 & 0.098 & (0.0238, & $0.170)$ & 0.037 & 0.008 & 0.025 \\
\hline APOE $\varepsilon 3-\varepsilon 4: \mathrm{HbA} 1 \mathrm{c}$ & 0.87 & -0.138 & $(-0.264$ & $-0.016)$ & 0.063 & 0.028 & 0.028 \\
\hline
\end{tabular}

APOE: apolipoprotein E; HDA1c: glycated hemoglobin. 
and MAP were pre-selected for modeling in accordance with the previously defined variables selection strategy $^{36}$ that sets our $\mathrm{p}$-value variable inclusion threshold at 0.1 . This model was selected based on our candidate variables (i.e., MAP, waist circumference, and HbA1c). Though MAP and waist circumference showed a relationship with the number of failed tests, they failed to show a joint relationship mediated by APOE genotypes ( $\mathrm{p}=0.14$ and 0.24 , respectively). In contrast, $\mathrm{HbA1}$ c presented a relationship with the APOE genotype and evidence of statistically significant interaction, revealing a strong interrelation. Specifically, we found that patients with the $\varepsilon 3-\varepsilon 4$ genotype have a 2.91 rate ratio for failed cognitive tests (Adj-p=0.027) compared to patients with the $\varepsilon 3-\varepsilon 3$ genotype. The number of failed tests would increase by a rate of $10 \%$ (Adj-p=0.025) for each one-unit increase in a patient's $\mathrm{HbA1c}$ values. Finally, we found a statistically significant interaction between the APOE genotype and the $\mathrm{HbA1c}$, revealing that the effect of the HbA1c was lower by $13 \%$ (Adj-p=0.028) in patients with the $\varepsilon 3-\varepsilon 4$ APOE genotype compare those with the $\varepsilon 3-\varepsilon 3$ genotype. The number of failed tests for patients in the APOE $\varepsilon 3-\varepsilon 3$ genotype group was more susceptible to being affected by HbA1c values than those in the APOE $\varepsilon 3-\varepsilon 4$ group, which already had much higher rates of failed test. We explored the effect of cardiometabolic factors such as prior diagnoses of hypertension and diabetes, weight, BMI, waist circumference and lipid values, and relevant variable interactions during the model building phase. However, it was not possible to find any other statistically significant relationships in multivariate models that included the APOE groups of interest. We would, therefore, provide the appropriate evidence to test our hypothesis.
This finding was explored further by predicting the counts of failed cognitive and memory tests rather than overall failures in our patient population (Table 5). Our final model predicting cognitive test failures only included the APOE variables, revealing a $19.4 \%$ higher number of failed cognitive tests for patients with the $\varepsilon 3-\varepsilon 4$ genotype compared to patients with the $\varepsilon 3-\varepsilon 3$ genotype (Adj-p<.0001). The univariate model predicting the number of failed cognitive tests based on the HbA1c did not reveal a statistically significant relationship (Adj-p=0.172). Still, the same model developed for the overall number of failed tests returned similar estimate values with near-significance before p-adjustment. For example, the APOE group differences returned a rates ratio of $2.55(\mathrm{p}=0.040)$ compared to 2.91 (Adj-p=0.027) and the HbA1c returned a rate ratio of 1.08 ( $\mathrm{p}=0.052)$ compared to 1.1 (Adj-p=0.025). This may be due to the reduced number of tests (i.e., cognitive tests only) and may be overcome with additional data. Other cardiometabolic factors were explored to predict the number of failed cognitive tests and relevant variable interactions during model building and development. For this model, we also explored the effect of the cardiometabolic factors stated above and relevant variable interactions. Still, it was not possible to find other statistically significant relationships for the models, including the APOE group variable. The possibility of modeling the number of failed memory tests only was also explored. However, no statistically significant relationships were found for the variables of interest. Our dataset presented zero-inflation $(69.3 \%$ of patients failed no memory tests), reducing our dataset variability and the potential for reliable statistical modeling.

Table 5. Final count regression results predicting the number of failed cognitive and memory tests for the full patient cohort.

\begin{tabular}{|c|c|c|c|c|c|c|c|c|}
\hline Model & Regression term & $\begin{array}{c}\text { Rates ratio } \\
(\exp (B))\end{array}$ & $\begin{array}{c}\text { Estimate } \\
\text { (B) }\end{array}$ & Confide & nterval & $\begin{array}{c}\text { Standard } \\
\text { error }\end{array}$ & p-value & $\begin{array}{c}\text { Adjusted } \\
\text { p-value }\end{array}$ \\
\hline \multirow{4}{*}{ Full model } & Intercept & 2.676 & 0.984 & $(0.469$ & $1.515)$ & 0.267 & 0.0002 & 0.001 \\
\hline & AP0E $\varepsilon 3-\varepsilon 4$ (Ref. 3-3) & 2.55 & 0.936 & $(0.052$ & $1.838)$ & 0.455 & 0.040 & 0.119 \\
\hline & $\mathrm{HbA1c}$ & 1.08 & 0.078 & $(-0.003$ & $0.155)$ & 0.040 & 0.052 & 0.119 \\
\hline & AP0E $\varepsilon 3-\varepsilon 4: \mathrm{HbA1C}$ & 0.892 & -0.114 & $(-0.247$ & $0.014)$ & 0.066 & 0.085 & 0.119 \\
\hline \multirow{2}{*}{ APOE only } & Intercept & 4.444 & 1.492 & $(1.404$ & 1.576) & 0.044 & $<.0001$ & $<.0001$ \\
\hline & AP0E ع3-ع4 (Ref. 3-3) & 1.194 & 0.177 & (0.009, & $0.341)$ & 0.085 & 0.036 & 0.036 \\
\hline
\end{tabular}

APOE: apolipoprotein E; HDA1c: glycated hemoglobin. 


\section{DISCUSSION}

We found that the number of failed cognitive tests in geriatric patients with cardiovascular risk factors was related to their APOE genotype and their HbA1c levels. Statistically significant differences were observed in the number of failed neuropsychological tests and APOE genotypes $\varepsilon 3-\varepsilon 3$ and $\varepsilon 3-\varepsilon 4$. $\varepsilon 3-\varepsilon 4$ genotype patients seemed to fail more cognitive tests. The HbA1c values at the time of testing appeared to affect the overall number of failed tests, but mostly in $\varepsilon 3-\varepsilon 3$ genotype patients. No HbA1c effect was found for cognitive tests alone.

Previous research established that the APOE gene is associated with the development of Alzheimer disease (AD). ${ }^{39}$ The E allele is also associated to code for the regulation of sugar and lipid metabolism. AD and MCI have a common pathway with diabetes and other metabolic disorders that could influence mechanisms for deterioration of cognitive functions. ${ }^{40}$ Significant positive association has been found in APOE $\varepsilon 4$ carriers, increasing the risk of developing vascular dementia as compared to $\varepsilon 2$ and $\varepsilon 3$ carriers. ${ }^{41}$ Our findings showed further differences in APOE alleles, underscoring an increased number of test failures in the $\varepsilon 3-\varepsilon 4$ as compared to the $\varepsilon 3-\varepsilon 3$ group. Furthermore, the length of time patients have diabetes is associated with greater cognitive decline after 20 years; this association is dependent on $\mathrm{HbA1c}$ levels, and greater cognitive decline observed with $\mathrm{HbA1}$ c > 7\%. ${ }^{9}$ Non-adherent diabetics also had worse performance in executive functions, memory tasks, and mental planning. ${ }^{42}$ The impairments were accentuated in cognitive domains such as information processing speed, executive function, ${ }^{9}$ memory loss, ${ }^{43}$ and visual construction skills, suggesting diabetes damages microvasculature of the subcortical gray matter or other pathways. Similarly, we found a strong association between HbA1c levels and VaMCI for the $\varepsilon 3-\varepsilon 3$ genotype in particular. In other investigations, cognitive performance was decreased in people with diabetes when educational differences were considered $;^{42}$ in our study, we found no association.

In previous studies, attention, executive function, and speed performance showed a decline when assessing for cognitive functions on patients with a continued hypertensive state ${ }^{44}$ with daily pressure variabilities associated with worse cognition and decreases in global cognitive functions..$^{45}$ Our data did not provide enough evidence to confirm the association between HTN and VaMCI. Similarly, two other studies observed that for every $10 \mathrm{mg}$ increase in small-dense low-density lipoprotein cholesterol (sdLDL-C), there was an accelerated cognitive deterioration. ${ }^{46} \mathrm{~A}$ high concentration of total cholesterol and LDL-C in late life was associated with a rapid cognitive impairment. On the contrary, another study found that MCI patients had a significant amount of small HDL when compared to the Alzheimer group, ${ }^{47}$ higher midlife HDL-C halve the risk of developing MCI and lowered risk of dementia later in life, ${ }^{48}$ suggesting an association between HDL subclasses and MCI. Whereas the components of MetS were not independently associated with cognitive impairment, MetS as a whole comprised a greater risk of developing accelerated cognitive decline at 10 years ${ }^{49}$ we did not find such association.

\section{Limitations and strengths}

Limitations included:

- The study population was relatively small and the resulting limited statistical power prevented the direct analysis of the relationship between cardiometabolic risk factors, APOE and MCI.

- Enrolled patients were from a single segment of the city.

- Our sample had a greater proportion of female participants.

- Participants were not matched according to educational level or age.

- Trial Making Test and Digit Span Tests were not included in the protocol due to financial limitation. There was a "floor effect" of the construction and abstract reasoning tests. The neuropsychological battery was developed to be used in Dominicans in New York, and we have implemented it in the Dominican Republic population; the years of education differences in these populations may have cause this floor effect.

- We analyzed only two of the APOE genotype groups with relatively different sizes due to limited proportion in some groups.

Study strengths:

- This is the first study in this population, and no comparisons of APOE 3-3 and 3-4 are available;

- The number of failed cognitive test allowed us to understand the magnitude of the impairment instead of encoding the presence or absence of VaMCI diagnosis.

Hemoglobin A1c and APOE genotypes seem to have an association with the development of VaMCI. Patients with APOE genotypes $\varepsilon 3-\varepsilon 3$ and $\varepsilon 3-\varepsilon 4$ are affected differently by A1c levels. In this sense, tight glucose control must be encouraged in the clinical consults for elderly patients at risk for developing VaMCI, in particular those with an $\varepsilon 3-\varepsilon 3$ and $\varepsilon 3-\varepsilon 4$ genotypes. 
Routine APOE genotyping and neuropsychological evaluation may be beneficial in the at-risk aged population of Latin-American and Dominican heritage. We found differences that should be explored in future research with larger patient cohorts to uncover further details about the relationship between APOE genotypes, cardiometabolic risk factors and $\mathrm{MCI}$.

\section{ACKNOWLEDGEMENT}

Genotyping for this project was supported by the Genetic Studies of Alzheimer's disease in Caribbean Hispanics (EFIGA) funded by the National Institute on Aging (NIA) and by the National Institutes of Health (NIH)
(5R37AG015473, RF1AG015473, R56AG051876). We acknowledge the EFIGA research and support staff for their contributions to this study.

Author's contributions. MM: conceptualization, methodology, funding acquisition, investigation, project administration, supervision, writing - original draft, writing - review \&amp; editing. RL: conceptualization, methodology, investigation. GS: conceptualization, methodology, investigation. SD: conceptualization, methodology, investigation. GCT: data curation, writing - original draft, writing - review \&amp; editing. PM: data curation. FDG: formal analysis, writing - review \&amp; editing. All authors reviewed the manuscript for final approval.

\section{REFERENCES}

1. World Health Organization. Dementia [accessed on Mar 3, 2020]. Available at: https://www.who.int/news-room/fact-sheets/detail/dementia

2. Sachdev PS, Valenzuela MJ, Brodaty H, Wang XL, Looi J, Lorentz L, et al. Homocysteine as a risk factor for cognitive impairment in stroke patients. Dement Geriatr Cogn Disord. 2003;15(3):155-62. https://doi. org/10.1159/000068481

3. O'Brien JT, Thomas A. Vascular dementia. Lancet. 2015;386(10004):1698706. https://doi.org/10.1016/S0140-6736(15)00463-8

4. Gorelick PB, Scuteri A, Black SE, De Carli C, Greenberg SM, ladecola C. Vascular contributions to cognitive impairment and dementia: a statement for healthcare professionals from the American heart association/American stroke association. Stroke. 2011;42:2672-13. https://doi.org/10.1161/ STR.0b013e3182299496

5. Chui HC, Ramirez-Gomez L. Clinical and imaging features of mixed Alzheimer and vascular pathologies. Alzheimers Res Ther. 2015;7(1):21. https://doi.org/10.1186/s13195-015-0104-7

6. Maldonado Villalón JA, Carranza Cervantes CA, Ortiz González MJ, Gómez Alonso C, Cortés-Gallegos NL. Prevalencia de factores de riesgo cardiometabólico en estudiantes universitarios de la región centro-occidente, en la Universidad Michoacana de San Nicolás de Hidalgo, México. Rev Mex Cardiol. 2013;24(2):76-86.

7. Zou Y, Zhu Q, Deng Y, Duan J, Pan L, Tu Q, et al. Vascular risk factors and mild cognitive impairment in the elderly population in Southwest China. Am J Alzheimers Dis Other Demen. 2014;29(3):242-7. https://doi. org/10.1177/1533317513517042

8. Qiu C, Winblad B, Fratiglioni L. The age-dependent relation of blood pressure to cognitive function and dementia. Lancet Neurol. 2005;4(8):487-99. https://doi.org/10.1016/S1474-4422(05)70141-1

9. Rawlings AM, Sharrett AR, Schneider ALC, Coresh J, Albert M, Couper D, et al. Diabetes in midlife and cognitive change over 20 years: a cohort study. Ann Intern Med. 2014;161(11):785. https://doi.org/10.7326/M14-0737

10. Biessels GJ, Staekenborg S, Brunner E, Brayne C, Scheltens P. Risk of dementia in diabetes mellitus: a systematic review. Lancet Neurol. 2006;5(1):64-74. https://doi.org/10.1016/S1474-4422(05)70284-2

11. Ivan CS, Seshadri S, Beiser A, Au R, Kase CS, Kelly-Hayes M, et al. Dementia after stroke: the Framingham Study. Stroke. 2004;35(6):1264-8. https://doi.org/10.1161/01.STR.0000127810.92616.78

12. Laudisio A, Marzetti E, Pagano F, Cocchi A, Franceschi C, Bernabei R, et al. Association of metabolic syndrome with cognitive function: the role of sex and age. Clin Nutr Edinb Scotl. 2008 Oct;27(5):747-54. https:// doi.org/10.1016/j.clnu.2008.07.001

13. Gatto NM, Henderson WW, St John JA, McCleary C, Hodis HN, Mack WJ. Metabolic Syndrome and Cognitive Function in Healthy Middle-Aged and Older Adults without Diabetes. Neuropsychol Dev Cogn B Aging Neuropsychol Cogn. 2008 Sep;15(5):627-41. https://doi. org/10.1080/13825580802036936

14. Jin YP, Ostbye T, Feightner JW, Di Legge S. Hachinski V: Joint effect of stroke and APOE 4 on dementia risk: the Canadian Study of Health andAging. Neurology. 2008;70(1):9-16. https://doi.org/10.1212/01. wnl.0000284609.77385.03
15. Reitz C. Toward precision medicine in Alzheimer's disease. Ann Transl Med. 2016 Mar;4(6):107-7. https://doi.org/10.21037/atm.2016.03.05

16. Romas SN, Santana V, Williamson J, Ciappa A, Lee JH, Rondon HZ, et. Al. Familial Alzheimer disease among Caribbean Hispanics: a reexamination of its association with APOE. Arch Neurol. 2002;59(1):87-91. https://doi. org/10.1001/archneur.59.1.87

17. Llewellyn DJ, Lang IA, Matthews FE, Plassman BL, Rogers MA, Morgenstern LB, et al. Vascular health, diabetes, APOE and dementia: the Aging, Demographics, and Memory Study. Alzheimers Res Ther. 2010;2(3):19. https://doi.org/10.1186/alzrt43

18. Yaffe K, Haan M, Blackwell T, Cherkasova E, Whitmer RA, West N. Metabolic syndrome and cognitive decline in elderly Latinos: findings from the Sacramento Area Latino Study of Aging study. J Am Geriatr Soc. 2007:55(5):758-62. https://doi.org/10.1111/j.1532-5415.2007.01139.x

19. Small BJ, Rosnick CB, Fratiglioni L, Bäckman L. Apolipoprotein E and cognitive performance: a meta-analysis. Psychol Aging. 2004;19(4):592600. https://doi.org/10.1037/0882-7974.19.4.592

20. Haan MN, Shemanski L, Jagust WJ, Manolio TA, Kuller L. The Role of APOE $€ 4$ in Modulating Effects of Other Risk Factors for Cognitive Decline in Elderly Persons. JAMA. 1999;282(1):40-6. https://doi.org/10.1001/ jama.282.1.40

21. Woodard JL. Geriatric Neuropsychological Assessment. In: Lichtenberg PA, Ed. Handbook of Assessment in Clinical Gerontology. 2nd ed. San Diego: Academic Press; 2010. p. 461-501 [accessed on Feb 3, 2020]. Available at: https://linkinghub.elsevier.com/retrieve/pii/ B9780123749611100181

22. Stern Y, Andrews H, Pittman J, Sano M, Tatemichi T, Lantigua R, et al. Diagnosis of dementia in a heterogeneous population. Development of a neuropsychological paradigm-based diagnosis of dementia and quantified correction for the effects of education. Arch Neurol. 1992;49(5):453-60. https://doi.org/10.1001/archneur.1992.00530290035009

23. Radloff LS. The CES-D Scale: a self-report depression scale for research in the general population. Appl Psychol Meas. 1977;1(3):385-401. https:// doi.org/10.1177/014662167700100306

24. Lawton MP, Brody EM. Assessment of older people: self-maintaining and instrumental activities of daily living. Gerontologist. 1969;9(3):179-86. https://doi.org/10.1093/geront/9.3_Part_1.179

25. Mahoney FI, Barthel DW. Functional evaluation: the Barthel index. Md State Med J. 1965;14:61-5.

26. Katzman R, Brown T, Fuld P, Peck A, Schechter R, Schimmel H. Validation of a short Orientation-Memory-Concentration Test of cognitive impairment. Am J Psychiatry. 1983;140(6):734-9. https://doi.org/10.1176/ ajp.140.6.734

27. Arnett DK, Blumenthal RS, Albert MA, Buroker AB, Goldberger ZD, Hahn EJ, et al. 2019 ACC/AHA Guideline on the Primary Prevention of Cardiovascular Disease: A Report of the American College of Cardiology/American Heart Association Task Force on Clinical Practice Guidelines. Circulation. 2019;140(11):e596-646 [accessed on Aug 24, 2020]. Available at: https://www.ahajournals.org/doi/10.1161/ CIR.0000000000000678 
28. Hixson JE, Vernier DT. Restriction isotyping of human apolipoprotein E by gene amplification and cleavage with Hhal. J Lipid Res. 1990;31(3):545-8. https://doi.org/10.1016/s0022-2275(20)43176-1

29. Rippon GA, Tang MX, Lee JH, Lantigua R, Medrano M, Mayeux R. Familial Alzheimer disease in Latinos: Interaction between APOE, stroke, and estrogen replacement. Neurology. 2006;66(1):35-40. https://doi. org/10.1212/01.wnl.0000191300.38571.3e

30. Maestre G, Ottman R, Stern Y, Gurland B, Chun M, Tang M-X, et al. Apolipoprotein $\mathrm{E}$ and Alzheimer's disease: Ethnic variation in genotypic risks. Ann Neurol. 1995;37(2):254-9. https://doi.org/10.1002/ana.410370217

31. Mattioli F, Stampatori C, Bellomi F, Scarpazza C, Capra R. Natalizumab Significantly Improves Cognitive Impairment over Three Years in MS: Pattern of Disability Progression and Preliminary MRI Findings. Linker RA, editor. PLOS ONE. 2015;10(7):e0131803. https://doi.org/10.1371/ journal.pone.0131803

32. Russo C, Morabito F, Luise F, Piromalli A, Battaglia L, Vinci A, et al. Hyperhomocysteinemia is associated with cognitive impairment in multiple sclerosis. J Neurol. 2008;255(1):64-9. https://doi.org/10.1007/s00415007-0668-7

33. R Core Team. R: A Language and Environment for Statistical Computing. Vienna, Austria: R Foundation for Statistical Computing; 2013 [accessed on March 20, 2020]. Available at: http://www.R-project.org/

34. van den Broek J. A Score Test for zero inflation in a Poisson distribution. Biometrics. 1995;51(2):738-43. https://doi.org/10.2307/2532959

35. Harrell FE, Lee KL, Mark DB. Multivariable prognostic models: issues in developing models, evaluating assumptions and adequacy, and measuring and reducing errors. Stat Med. 1996;15(4):361-87. https://doi. org/10.1002/(SICl)1097-0258(19960229)15:4<361::AID-SIM168>3.0. $\mathrm{CO} ; 2-4$

36. Pan W. Akaike's Information Criterion in Generalized Estimating Equations. Biometrics. 2001;57(1):120-5. https://doi.org/10.1111/j. 0006-341x.2001.00120.x

37. Aickin M, Gensler H. Adjusting for multiple testing when reporting research results: the Bonferroni vs Holm methods. Am J Public Health. 1996;86(5):726-8. https://doi.org/10.2105/ajph.86.5.726

38. Zhao N, Liu C-C, Qiao W, Bu G. Apolipoprotein E, Receptors and modu lation of Alzheimer's disease. Biol Psychiatry. 2018;83(4):347-57. https:// doi.org/10.1016/j.biopsych.2017.03.003

39. Cheng $\mathrm{G}$, Huang $\mathrm{C}$, Deng $\mathrm{H}$, Wang $\mathrm{H}$. Diabetes as a risk factor for dementia and mild cognitive impairment: a meta-analysis of longitudinal studies: Diabetes and cognitive function. Intern Med J. 2012;42(5):484-91. https:// doi.org/10.1111/j.1445-5994.2012.02758.x
40. Liu X, Li L, Liu F, Deng S, Zhu R, Li Q, et al. ApoE gene polymorphism and vascular dementia in Chinese population: a meta-analysis. J Neural Transm. 2012;119(3):387-94. https://doi.org/10.1007/s00702-0110714-6

41. Cerezo-Huerta K, Yáñez-Téllez G, Aguilar-Salinas CA. Funcionamiento ejecutivo y adherencia terapéutica en la diabetes mellitus tipo 2. Arch Neurocienc Mex INNN. 23(3):42-53. https://doi.org/10.31157/archneurosciencesmex.v23i3.17

42. Marden JR, Mayeda ER, Tchetgen Tchetgen EJ, Kawachi I, Glymour MM High Hemoglobin A1c and Diabetes Predict Memory Decline in the Health and Retirement Study: Alzheimer Dis Assoc Disord. 2017;31(1):48-54. https://doi.org/10.1097NAD.0000000000000182

43. Overman MJ, Pendleton N, O'Neill TW, Bartfai G, Casanueva FF, Forti $\mathrm{G}$, et al. Glycemia but not the Metabolic Syndrome is Associated with Cognitive Decline: Findings from the European Male Ageing Study. Am J Geriatr Psychiatry. 2017;25(6):662-71. https://doi.org/10.1016/j. jagp.2017.02.004

44. Goldstein FC, Levey Al, Steenland NK. High Blood Pressure and Cognitive Decline in Mild Cognitive Impairment. J Am Geriatr Soc. 2013;61(1):67-73. https://doi.org/10.1111/jgs.12067

45. McDonald C, Pearce MS, Kerr SRJ, Newton JL. Blood pressure variability and cognitive decline in older people: a 5-year longitudinal study. J Hypertens. 2017;35(1):140-7. https://doi.org/10.1097/ HJH.0000000000001120

46. Pokharel Y, Mouhanna F, Nambi V, Virani SS, Hoogeveen R, Alonso A, et al. ApoB, small-dense LDL-C, Lp(a), LpPLA 2 activity, and cognitive change. Neurology. 2019;92(22):e2580-93. https://doi.org/10.1212/ WNL.0000000000007574

47. Ohtani R, Nirengi S, Nakamura M, Murase N, Sainouchi M, Kuwata Y, et al. High-Density Lipoprotein Subclasses and Mild Cognitive Impairment: Study of Outcome and aPolipoproteins in Dementia (STOP-Dementia)1. J Alzheimers Dis. 2018;66(1):289-96. https://doi.org/10.3233/ JAD-180135

48. Svensson T, Sawada N, Mimura M, Nozaki S, Shikimoto R, Tsugane S. The association between midlife serum high-density lipoprotein and mild cognitive impairment and dementia after 19 years of follow-up. Trans Psychiatry. 2019;9(1):26. https://doi.org/10.1038/s41398-018-0336-y

49. Viscogliosi G, Donfrancesco C, Palmieri L, Giampaoli S. The metabolic syndrome and 10-year cognitive and functional decline in very old men. A population-based study. Arch Gerontol Geriatr. 2017;70:62-6. https:// doi.org/10.1016/j.archger.2016.12.008 